\title{
Relationship between individual payload weight and spondylolysis incidence in Turkish land forces
}

\author{
Emrah Celtikci, MD, ${ }^{1,2}$ Fatih Yakar, MD, ${ }^{2}$ Pinar Celtikci, MD, ${ }^{3}$ and Yusuf Izci, MD ${ }^{4}$ \\ 1Department of Neurosurgery, Gazi University Faculty of Medicine, Ankara; ${ }^{2}$ Department of Neurosurgery, Kars Harakani State \\ Hospital, Kars; ${ }^{3}$ Department of Radiology, Kars Harakani State Hospital, Kars; and ${ }^{4}$ Department of Neurosurgery, University of \\ Health Sciences, Gulhane Education and Research Hospital, Ankara, Turkey
}

\begin{abstract}
OBJECTIVE The aim of this study was to investigate the relationship between lumbar spondylolysis and payload weight between different combat units of Turkish land forces (TLF).

METHOD The authors reviewed clinical and radiological data of the military personnel with low-back pain (LBP) admitted to their clinic between July 2017 and July 2018. Age, BMI, average payload weight, and military service unit were recorded. CT scans were evaluated for pars interarticularis fractures and spondylolisthesis, whereas MRI studies were evaluated for spondylolisthesis, Modic-type endplate changes, or signal loss on T2-weighted images compatible with disc degeneration.

RESULT Following exclusion, a total of 642 all-male military personnel were included. Of these personnel, 122 were commandos, 435 were infantry, and 85 were serving in the artillery units. Bilateral pars interarticularis fracture was noted in 42 commandos $(34.42 \%)$ and 2 infantrymen $(0.45 \%)$. There was no spondylolysis in the artillery units. There was no multiple-level spondylolysis and the most common level of spondylolysis was L5. Commandos had a significantly higher incidence of spondylolysis and more average payload weight $(p<0.001)$. Twelve patients $(27.2 \%)$ with spondylolysis had accompanying MRI pathologies at the same level, whereas 32 patients $(72.7 \%)$ had no accompanying MRI pathologies.

CONCLUSIONS Increased payload weight in military personnel is associated with spondylolysis, and commandos in the TLF have significantly heavier payloads, which causes an increased rate of spondylolysis compared to other units. Additionally, spondylolysis without adjacent-level changes on MRI could be undiagnosed. LBP in active military personnel who have a history of carrying heavy payloads should be evaluated extensively with both MRI and CT scans.

https://thejns.org/doi/abs/10.3171/2018.8.FOCUS18375
\end{abstract}

KEYWORDS land forces; payload weight; spondylolysis; fractures; stress

$\mathrm{T}$ Jhe Turkish Armed Forces (TAF) collectively rank as the second largest standing military force in the North Atlantic Treaty Organization (NATO), after the US Armed Forces. ${ }^{5}$ In recent years, Turkish land forces (TLF) have been involved in cross-border operations such as Operation Olive Branch and Operation Euphrates Shield. In the meantime, domestic anti-terror operations against terrorist insurgency groups, which are currently the major activity of the TLF, have continued. In such anti-terror operations, a special group of soldiers who are specialized in combat against terrorist groups in a mountainous terrain, i.e., commandos, take the most active role. Thus, commandos are the most physically challenged group of soldiers in TLF.

It is already known that during operations and operational training, overuse stress injuries are encountered in army personnel around the world..$^{4,9-11,14,15,20}$ In the US, the estimated cost for these kind of injuries is $\$ 20$ billion. ${ }^{3}$ It is necessary to implement a surveillance system for active military personnel injuries in order to prevent such diseases, ${ }^{2}$ however, TAF does not yet have such a surveillance system.

Spondylolysis is a weakness or stress fracture in one of the bone bridges that connect the upper with the lower facet joints of the spinal column. The frequency of spondylolysis is as high as $6 \%$ of the population. ${ }^{26}$ Spondylolysis is a common cause of low-back pain (LBP) and most commonly affects gymnasts, football linemen, weightlifters, wrestlers, dancers, and drivers. This condition is aggravated by physical activity. CT, in particular high-definition multiplanar imaging devices, and MRI are the diagnostic tools of spondylolysis. ${ }^{26}$

In this study we investigated the frequency of spondylolysis in a particular troop of TLF, i.e., commandos,

ABBREVIATIONS BMD = bone mineral density; $\mathrm{LBP}=$ low-back pain; TAF = Turkish Armed Forces; $T L F=$ Turkish land forces.

SUBMITTED July 28, 2018. ACCEPTED August 27, 2018.

INCLUDE WHEN CITING DOI: 10.3171/2018.8.FOCUS18375. 
TABLE 1. Patient characteristics, payload weight, and incidence of pars interarticularis fracture in subjected military personnel

\begin{tabular}{ccccc}
\hline & \multicolumn{4}{c}{ Military Class } \\
\cline { 2 - 5 } Variable & $\begin{array}{c}\text { Commando } \\
(\mathrm{n}=122)\end{array}$ & $\begin{array}{c}\text { Infantry } \\
(\mathrm{n}=435)\end{array}$ & $\begin{array}{c}\text { Artillery Unit } \\
(\mathrm{n}=85)\end{array}$ & $\begin{array}{c}\mathrm{p} \\
\text { Value }\end{array}$ \\
\hline Mean age $\pm \mathrm{SD}$, yrs & $23.1 \pm 3.6$ & $22.8 \pm 2.1$ & $22.9 \pm 3.1$ & 0.525 \\
\hline $\begin{array}{c}\text { Mean BMI } \pm \mathrm{SD}, \\
\mathrm{kg} / \mathrm{m}^{2}\end{array}$ & $22.9 \pm 2.4$ & $22.6 \pm 2.9$ & $22.7 \pm 1.9$ & 0.552 \\
\hline $\begin{array}{c}\text { Average payload } \\
\text { carried } \pm \text { SD, kg }\end{array}$ & $38.71 \pm 3$ & $8.2 \pm 4.5$ & $7.9 \pm 4.1$ & $<0.001$ \\
\hline $\begin{array}{c}\text { No. w/ pars interar- } \\
\text { ticularis fracture } \\
(\%)\end{array}$ & $42(34.42)$ & $2(0.45)$ & $0(0)$ & $<0.001$ \\
\hline
\end{tabular}

based on the experiences of neurosurgeons performing both civilian and military medicine service in the city of Kars and its vicinity. The aims of this study were to compare the incidence of spondylolysis between commando troops and other military personnel based on their age, BMI, and payload weight; to understand the etiology and preventive measures of this spinal disease that may provide valuable information for the TAF; and to share the lessons learned from these groups of patients.

\section{Methods \\ Data Collection}

The study was performed in Kars Harakani State Hospital, the only official neurosurgical care provider for the TAF in the city of Kars and its vicinity. Two neurosurgeons retrospectively reviewed clinical and radiological data of the military personnel with LBP, including those admitted as inpatients and outpatients, between July 2017 and July 2018. In accordance with TAF Health and Welfare Regulation, all military personnel underwent a full medical examination prior to recruitment and none of the study participants had a history of LBP or spondylolysis prior to active duty. The inclusion criterion was having received both CT and MRI scans in the same admission. All patients with spondylolysis had bone mineral density (BMD) scans. Age, BMI, average payload weight, and military service unit were recorded. Payload weight is the total weight a soldier carries during an active operation, which comprises weapons, ammunition, nutritional and medical supplies, communication devices, and protective gear. Payload weight does not include soldiers' own weight. Exclusion criteria were noncombatant or any military personnel other than TLF (such as Air Force or Navy), history of trauma, BMI less than $18.5 \mathrm{~kg} / \mathrm{m}^{2}$ or more than $25 \mathrm{~kg}$ / $\mathrm{m}^{2}$, complaint other than LBP, and admission to the emergency service rather than the outpatient clinic. All imaging data were evaluated by a radiologist. CT scans were evaluated for pars interarticularis fractures and spondylolisthesis, whereas MRI studies were evaluated for spondylolisthesis, Modic-type endplate changes, or signal loss in T2-weighted images compatible with disc degeneration.

Follow-up data regarding the spondylolysis group were not possible to acquire as TAF Health and Welfare Regulation dictates referral of spondylolysis cases to a tertiary

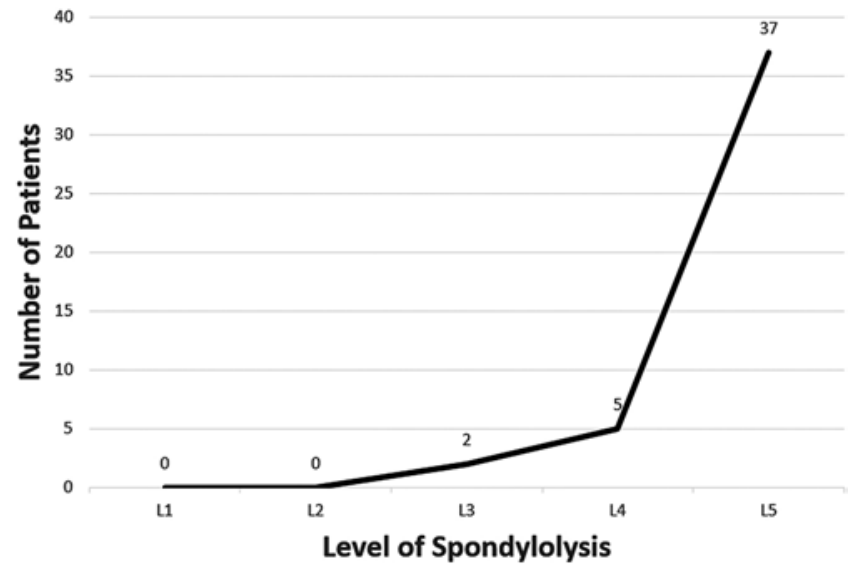

FIG. 1. Line graph demonstrating the distribution of patients according to level of spondylolysis.

healthcare center, unless an emergency surgical intervention is required.

\section{Statistical Analysis}

SPSS (version 20, IBM Corp.) was utilized for statistical analysis. Descriptive statistics were explored using mean and standard deviation for quantitative data and frequency and percentage for qualitative variables. Oneway ANOVA was used to reveal any significant difference between distribution of variances. A comparison of proportions test was used to check any significant difference between percentages. Alpha was set at 0.5 and a $p$ value $<$ 0.05 was considered significant.

\section{Results}

Following exclusion, a total of 642 all-male military personnel of the TLF comprised the study cohort. Of these personnel, 122 were commandos, 435 were infantry, and 85 were serving in the artillery units. Patient characteristics were summarized in Table 1 . No statistical difference was found in age and BMI distribution of patients ( $\mathrm{p}$ $=0.525$ and $\mathrm{p}=0.552$, respectively; Table 1 ).

Bilateral pars interarticularis fracture was noted in 42 commandos $(34.42 \%)$ and 2 infantrymen $(0.45 \%)$. No unilateral pars interarticularis fracture was detected. All pars interarticularis fractures had corticated fracture margins that were compatible with a chronic traumatic process. No osteopenia or osteoporosis was detected in BMD examinations of these patients. There were no pars interarticularis fractures in artillery units. Statistical analysis revealed commandos had a significantly higher incidence of spondylolysis and more average payload weight $(\mathrm{p}<$ 0.001; Table 1). All 42 commandos with spondylolysis had been involved in at least one anti-terror operation requiring a payload weight ranging between 34 and $45 \mathrm{~kg}$ (mean $38.71 \pm 3 \mathrm{~kg}$ ). In contrast, infantry and artillery units had a significantly lower incidence of spondylolysis and less average payload weight (Table 1).

There was no multiple-level spondylolysis and the most common level of spondylolysis was L5 $(\mathrm{n}=37)$, followed by L4 $(n=5)$ and L3 ( $n=2$; Fig. 1). Twelve patients 

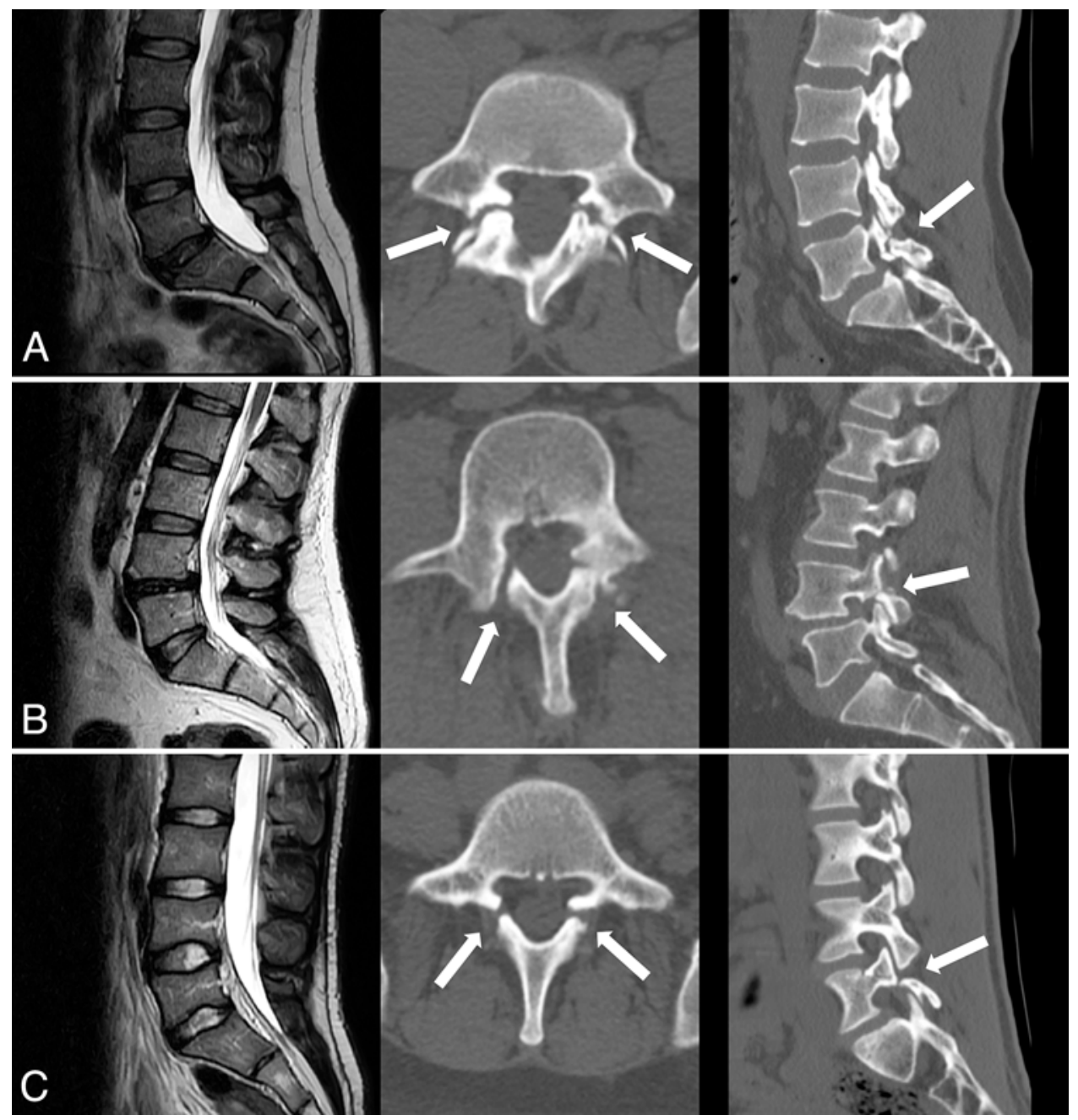

FIG. 2. Sagittal T2-weighted MR images (left column), axial CT scans (middle column), and sagittal CT images (right column) of 3 patients with pars interarticularis fractures (arrows). MRI of the lumbar spine could demonstrate accompanying adjacent-level pathologies such as signal loss on T2-weighted images that are compatible with disc degeneration (A) or spondylolisthesis (B). The majority of patients with spondylolysis in our study had no detectable adjacent-level pathologies on MRI (C).

(27.2\%) with spondylolysis had accompanying MRI pathologies at the same level, whereas 32 patients $(72.7 \%)$ had no accompanying MRI pathologies. Examples of pars interarticularis fractures and accompanying lesions are demonstrated in Fig. 2.

\section{Discussion}

In this study we demonstrated that commandos, a special force of the TAF, are more likely to have spondylolysis, most commonly in the L5 level. This group of soldiers also has more average payload weight compared to other units, which is the probable cause of repeated microtrauma and resulting stress fracture of the pars interarticularis. Increased individual payload of active military personnel during training or operations is a significant risk factor for pars interarticularis fractures of the lumbar spine.

The posterior column of the spine carries approximately one-third of the load, and axial loads of the posterior column are transferred via ligaments and facets of each segmental level. The incidence of lumbar spondylolysis in asymptomatic soldiers prior to military placement was reported as $9.7 \%$ in a study performed within the Israeli Defense Forces. ${ }^{12}$ Also, spondylolysis is a common problem among populations who are prone to repeated microtrauma, such as young athletes. ${ }^{1,13,17,27}$ These kinds of stress injuries are commonly termed as overuse injuries and there are several reports investigating this health problem in military personnel. , $, 7,14,20,22,24$ Previous reports demonstrated different incidences of stress injury between military troops. ${ }^{14}$ However, to the best of our knowledge, the relationship between spondylolysis of the lumbar spine and individual payload weight has not yet been investigated.

Individual properties of a soldier, such as body weight, could provide an inclination for a stress injury. ${ }^{4,10}$ Thus, in our study we have excluded patients who had a BMI other than normal range. As there were no significant differences regarding BMI among various groups of land forces, the increased incidence of spondylolysis in commando troops led us to search for the underlying reasons. 
A commando is a soldier who is often specialized in amphibious landings, parachuting, or rappelling (https:// en.wikipedia.org/wiki/commando). Commandos are subject to a more rigorous selection process and undergo more arduous training compared to other military infantry troops..$^{25}$ During an operation, a regular commando carries a backpack that composes the majority of the individual payload. The physical activity is more demanding and the weights that the soldiers must carry are significantly greater for commandos compared to other soldiers. A physically strenuous lifestyle (like that led by commandos) is associated with premature degeneration of the musculoskeletal system. Moreover, weightlifting combined with this lifestyle can cause serious musculoskeletal injuries, such as ruptured intervertebral discs, spondylolysis and spondylolisthesis, fractures, and meniscal injuries of the knee. ${ }^{16}$ Commando troops have some long-standing military duties and during that time they perform heavy lifting for a long time period. Long-standing vocational heavy lifting may be a factor in the development of spondylolysis and LBP. A retrospective study that investigated the etiology of LBP in soldiers deployed to Afghanistan showed that carrying heavier loads increased the risk of LBP in deployed soldiers. ${ }^{18}$ During a military operation, a heavy backpack will increase compression and flexion forces on the spinal column. Additional axial rotation will generate the highest stress on the lumbar spine, which is related to the risk of spondylolysis. ${ }^{23}$

Degenerative spinal disorders, spondylolisthesis, rheumatoid arthritis, ankylosing spondylitis, and scoliosis may be associated with spondylolysis. The differential diagnosis is very important in these conditions for an accurate management protocol. In countries in which the health system provides easier accessibility, MRI is usually the first modality of imaging for LBP. This choice is also facilitated with the chronic nature of the complaint in spondylolysis due to stress fracture of the pars interarticularis. One of the lessons learned from this retrospective study is that in $72.7 \%$ of patients with LBP and spondylolysis there were no accompanying MRI pathologies. Although previous reports showed adjacent-level changes in MRI accompanying lumbar spondylolysis,,${ }^{6,8,19,21}$ our study demonstrated spondylolysis could be present without any significant MRI findings. Therefore, even if there is no detectable spondylolisthesis, Modic-type endplate changes, or disc degeneration on MRI, LBP should be investigated via $\mathrm{CT}$, especially in military units with a heavy payload, in order to detect spondylolysis. Sole MRI evaluation of these patients may lead to a late diagnosis of spondylolysis that would cause a delay in treatment and further degeneration.

All the spondylolysis cases that we have detected in this study had radiological findings that were compatible with chronic processes such as corticated fracture margins. As stress injuries do not result from acute trauma, this is the expected appearance and finding that supports the diagnosis of stress-induced pars interarticularis fracture due to chronic trauma.

TAF Health and Welfare Regulation states that if a commando soldier is diagnosed with spondylolysis, then he/she must be removed from commando class and re- assigned to another combat class. This health problem, which we have demonstrated to be linked with heavy individual payload weight, causes loss of specialized military personnel in the TAF. As it takes a significant amount of time and effort to train commando-class soldiers, preventive measures such as decreasing payload weight, reforming supply chains, and application of robotic weight-bearing technologies are warranted.

This study has some limitations. First, it comprises limited retrospective data of a specific region. Second, our study cohort includes units who are assigned for anti-terror operations against terrorist groups in a mountainous terrain, which may not represent the overall population of the TAF. Third, the study cohort includes only male soldiers as there were no female soldiers in the study population.

\section{Conclusions}

LBP in active military personnel who have a history of carrying heavy payloads should be evaluated extensively. Increased payload weight is associated with spondylolysis and commandos in the TLF have significantly heavier payloads, which causes an increased rate of spondylolysis compared to other units. Additionally, spondylolysis without adjacent-level changes on MRI could be undiagnosed. Therefore, we recommend performing both MRI and CT scans if a soldier with LBP has a history of carrying heavy payloads. Future studies are warranted for protective equipment development in order to prevent heavy payloadrelated spinal injuries in military personnel.

\section{References}

1. Amato M, Totty WG, Gilula LA: Spondylolysis of the lumbar spine: demonstration of defects and laminal fragmentation. Radiology 153:627-629, 1984

2. Bullock SH, Jones BH, Gilchrist J, Marshall SW: Prevention of physical training-related injuries recommendations for the military and other active populations based on expedited systematic reviews. Am J Prev Med 38 (1 Suppl):S156-S181, 2010

3. Cloeren M, Mallon TM: Managing workers' compensation costs in the military setting: the Army's story. Clin Occup Environ Med 4:vii, 323-339, 2004

4. Darakjy S, Marin RE, Knapik JJ, Jones BH: Injuries and illnesses among armor brigade soldiers during operational training. Mil Med 171:1051-1056, 2006

5. Global Firepower. Total available active military manpower by country. Globalfirepower.com (https://www. globalfirepower.com/active-military-manpower.asp) [Accessed October 10, 2018]

6. Goda Y, Sakai T, Harada T, Takao S, Takata Y, Higashino K, et al: Degenerative changes of the facet joints in adults with lumbar spondylolysis. Clin Spine Surg 30:E738-E742, 2017

7. Hauret KG, Jones BH, Bullock SH, Canham-Chervak M, Canada S: Musculoskeletal injuries description of an underrecognized injury problem among military personnel. Am J Prev Med 38 (1 Suppl):S61-S70, 2010

8. Hsieh CC, Wang JD, Lin RM, Lin CJ, Huang KY: Adjacent disc and facet joint degeneration in young adults with lowgrade spondylolytic spondylolisthesis: a magnetic resonance imaging study. J Formos Med Assoc 114:1211-1215, 2015

9. Kaufman KR, Brodine S, Shaffer R: Military trainingrelated injuries: surveillance, research, and prevention. Am J Prev Med 18 (3 Suppl):54-63, 2000 
10. Knapik JJ, Sharp MA, Montain SJ: Association between stress fracture incidence and predicted body fat in United States Army Basic Combat Training recruits. BMC Musculoskelet Disord 19:161, 2018

11. Kunte R, Basannar D, Chatterjee K, Agarwal PK, Prasad L, Dubey P, et al: Gender differential and implications in the epidemiology of stress fractures among cadets of Indian Armed Forces. Med J Armed Forces India 73:356-362, 2017

12. Libson E, Bloom RA, Dinari G: Symptomatic and asymptomatic spondylolysis and spondylolisthesis in young adults. Int Orthop 6:259-261, 1982

13. Reitman CA, Gertzbein SD, Francis WR Jr: Lumbar isthmic defects in teenagers resulting from stress fractures. Spine $\mathbf{J}$ 2:303-306, 2002

14. Reynolds K, Cosio-Lima L, Bovill M, Tharion W, Williams J, Hodges T: A comparison of injuries, limited-duty days, and injury risk factors in infantry, artillery, construction engineers, and special forces soldiers. Mil Med 174:702-708, 2009

15. Rice HM, Saunders SC, McGuire SJ, O’Leary TJ, Izard RM: Estimates of tibial shock magnitude in men and women at the start and end of a military drill training program. Mil Med [epub ahead of print], 2018

16. Risser WL: Weight-training injuries in children and adolescents. Am Fam Physician 44:2104-2108, 1991

17. Roche MB, Rowe GG: The incidence of separate neural arch and coincident bone variations; a survey of 4,200 skeletons. Anat Rec 109:233-252, 1951

18. Roy TC, Lopez HP, Piva SR: Loads worn by soldiers predict episodes of low back pain during deployment to Afghanistan. Spine (Phila Pa 1976) 38:1310-1317, 2013

19. Schlenzka D, Poussa M, Seitsalo S, Osterman K: Intervertebral disc changes in adolescents with isthmic spondylolisthesis. J Spinal Disord 4:344-352, 1991

20. Schwartz O, Malka I, Olsen CH, Dudkiewicz I, Bader T: Overuse injuries in the IDF's combat training units: rates, types, and mechanisms of injury. Mil Med 183:e196-e200, 2018

21. Seitsalo S, Schlenzka D, Poussa M, Osterman K: Disc degeneration in young patients with isthmic spondylolisthesis treated operatively or conservatively: a long-term follow-up. Eur Spine J 6:393-397, 1997
22. Smith TA, Cashman TM: The incidence of injury in light infantry soldiers. Mil Med 167:104-108, 2002

23. Sterba M, Arnoux PJ, Labelle H, Warner WC, Aubin CÉ: Biomechanical analysis of spino-pelvic postural configurations in spondylolysis subjected to various sport-related dynamic loading conditions. Eur Spine J [epub ahead of print], 2018

24. Strowbridge NF, Burgess KR: Sports and training injuries in British soldiers: the Colchester Garrison Sports Injury and Rehabilitation Centre. J R Army Med Corps 148:236-243, 2002

25. Sundin J, Jones N, Greenberg N, Rona RJ, Hotopf M, Wessely S, et al: Mental health among commando, airborne and other UK infantry personnel. Occup Med (Lond) 60:552559,2010

26. Syrmou E, Tsitsopoulos PP, Marinopoulos D, Tsonidis C, Anagnostopoulos I, Tsitsopoulos PD: Spondylolysis: a review and reappraisal. Hippokratia 14:17-21, 2010

27. Warner WC Jr, de Mendonça RGM: Adolescent spondylolysis: management and return to play. Instr Course Lect 66:409-413, 2017

\section{Disclosures}

The authors report no conflict of interest concerning the materials or methods used in this study or the findings specified in this paper.

\section{Author Contributions}

Conception and design: E Celtikci, Yakar. Acquisition of data: E Celtikci, Yakar, P Celtikci. Analysis and interpretation of data: E Celtikci, P Celtikci. Drafting the article: E Celtikci, P Celtikci. Critically revising the article: P Celtikci, Izci. Reviewed submitted version of manuscript: all authors. Approved the final version of the manuscript on behalf of all authors: E Celtikci. Statistical analysis: E Celtikci. Administrative/technical/material support: Yakar, Izci. Study supervision: Izci.

\section{Correspondence}

Emrah Celtikci: Gazi University Faculty of Medicine, Ankara, Turkey.drceltikci@gmail.com. 